\title{
Kinetics and Thermodynamics Investigations on Corrosion Inhibiting Properties of Coffee Husks Extract on Mild Steel in Acidic Medium
}

\author{
Kalisa Nyirimbibi Daniel ${ }^{\mathrm{a}}$, Muhizi Theoneste ${ }^{\mathrm{a}}$, Niyotwizera Jean Jacques Yves ${ }^{\mathrm{a}}$, Barutwanayo \\ Jean Baptiste $^{\mathrm{a}}$ and Nkuranga Jean Bosco ${ }^{\mathrm{a}, \mathrm{b}}$ \\ a Department of Chemistry, College of Science and Technology, University of Rwanda, \\ P.O.Box.3900, Rwanda. \\ ${ }^{\boldsymbol{b}}$ Chemistry Department, College of Natural and Applied Sciences, University of Dar es Salaam, \\ Tanzania. \\ *Corresponding author: nkalisa@gmail.com Tel: +250788502502
}

\begin{abstract}
In this study, the use of green corrosion inhibitors extracted from coffee husks was investigated on mild steel materials in acidic medium. Phenolic compounds from coffee husks were extracted using acetone solvent, characterised and investigated for their corrosion inhibiting properties. The FTIR and ${ }^{1} \mathrm{H}-\mathrm{NMR}$ technique were carried out to characterise the present phenolic compounds extracted from purified coffee husks. The corrosion inhibition efficiency of phenolic compounds from coffee husks extract on mild steel in $1.0 \mathrm{M} \mathrm{HCl}$ was evaluated by using weight loss method. The obtained results showed that corrosion rates decreased with the increase of inhibitor concentration, temperature and immersion time. The optimum inhibition efficiency of $86.5 \%$ at $25^{\circ} \mathrm{C}$ was obtained with a concentration of $400 \mathrm{mg} / \mathrm{L}(400 \mathrm{ppm})$ of coffee husks extract in two hours of experiment. The observed inhibition efficiency was attributed to the physical adsorption mechanism of phenolic compounds on mild steel surface through charged ion formation from protonation of lone pairs of oxygen in phenol or ionic dissociation of carboxylic acid functional group that formed a charged layer over mild steel surface. Furthermore, it was pointed out that the adsorption process obeyed the Langmuir adsorption isotherm model at all investigated temperatures between 25 and $40^{\circ} \mathrm{C}$.
\end{abstract}

Keywords: Corrosion inhibitor, phenolic compounds, coffee husks extract, mild steel, adsorption. 


\section{INTRODUCTION}

Corrosion is a natural phenomenon, which can be chemical or electrochemical in nature that causes metals, ceramics and alloys degradation, and then make them useless for their expected utility (Nwosu and Muzakir, 2016, Hariom, et al., 2016). This phenomenon constitutes a major industrial concern due to some industrial processes including acid cleaning, pickling and descaling, which enhance contact between metal and aggressive corrosive media such as mineral acids, bases, salts, air and water (Ghareba and Omanovic, 2011, Singh, et al. 2017). Naturally, all metals except gold are thermodynamically unstable with respect to their oxides. So corrosion of metals represents the tendency of pure metals and alloys to return to thermodynamically more stable compounds e.g. oxides, sulphide, carbonate, hydroxides, chlorides, etc. This is due to their electrochemical potentials at environmental conditions (Waite and Nelsen, 2005). So, the corrosion process returns the metals to their stable states that are similar or even identical to the minerals from which they were extracted, thus corrosion is a spontaneous process. Based on electrochemistry principles and thermodynamic laws, the prediction of regions of corrosion, passivity and immunity of iron metal/alloys in aerated and de-aerated acidic media can be predicted by using the Pourbaix diagram. A relatively simple potential - $\mathrm{pH}$ diagram for a metal iron is shown in Figure 1.

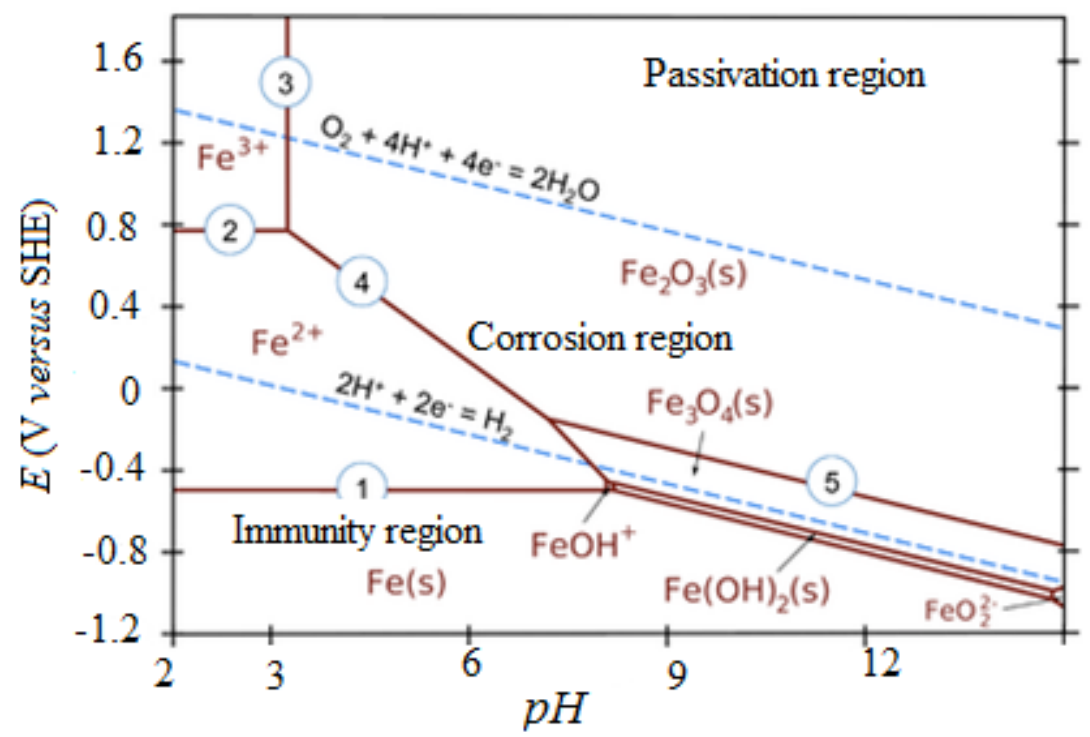

Figure 1: Potential-pH diagram for iron in aerated and deaerated acidic and aqueous medium at $25{ }^{\circ} \mathrm{C}$ (Uhlig and Revie, 2015). 
Due to its cost effectiveness and high mechanical resistance, mild steel is widely used as structural material in several industrial and building activities as well as in fluid transport as pipeline and other daily applications (Senthil, et al., 2016). However, this useful material is known to be seriously threatened by corrosion if it is not protected. There exist several ways of mitigating corrosion such as anodization, electroplating, painting, modification of the corrosive environment and use of corrosion inhibitors (Philip, et al., 2016). Corrosion inhibitors can be natural or synthetic, organic or inorganic. However, the use of the plant extract or plant derived corrosion inhibitors was found to be the economical and environmentally friendly way for mitigating corrosion (Philip, et al., 2016). Plant extract corrosion inhibitors are widely used in industry to reduce the corrosion rate of metals and alloys in contact with aggressive environment (Nwosu and Muzakir, 2016). This is because plant extract inhibitors are largely non-toxic, environmentally benign, renewable and biodegradable (Rajendran, et al., 2005, Rani and Basu, 2012). Some of the plant materials that were reported to possess corrosion inhibiting properties include Hemidesmus indicus leaves, Mansoalliacea punica leaves, Phoenix dactylifera leaves, Ziziphus mauritiana fruit, Carica papaya leaves, Stevia rebaudiana leaves and its unripe fruit peel, Argemone Mexicana leaves, leaves and stem bark of Xylopiaferruginea plant, and leaves, bark and roots of Nauclealatifolia extract (Rajendran et al., 2005). The mechanism by which these plant extract inhibit metal corrosion process were associated to the presence of heteroatoms such as oxygen, nitrogen, sulphur, phosphorus and $\pi$-electron systems that favour chemisorption on the metal surface, thus isolating the metal surface exposure to the corrosive medium in which the metal is used (Rani and Basu, 2012).

The choice of organic corrosion inhibitors could be thought as covering a wide range of organic compounds; however, the use of some synthetic organic corrosion inhibitors was hindered by their toxicity and costs. For this purpose, green corrosion inhibitors extracted from plants were envisaged as alternative. Based on chemical structures of phenols, phenolic compounds are expected to be potential for being used as organic corrosion inhibitors. Unfortunately, phenols were reported to be non-environmentally friendly because they are non-biodegradable, thus requiring a special treatment or removal before their release into environment. Coffee and coffee husks were reported to be rich in different phenolic compounds. Some of phenolic compounds are given in Figure 2 (Farah and Donangelo 2006, Dai and Mumper, 2010, Vasconcelos et al., 2011). 

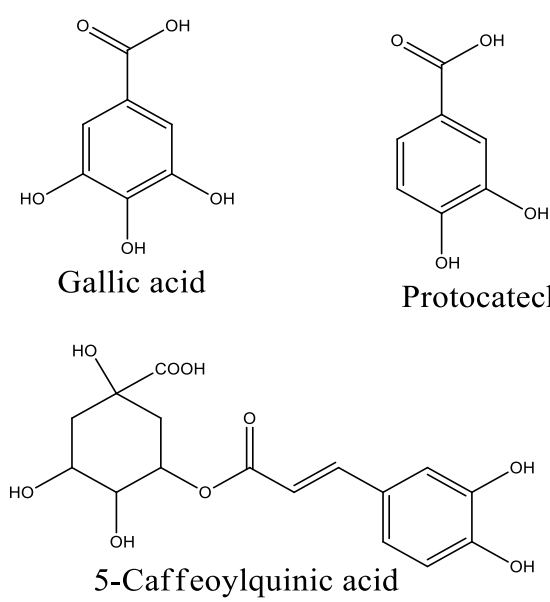

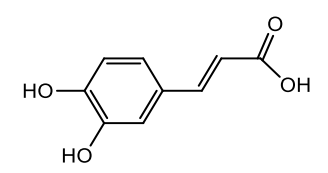

Caffeic acid

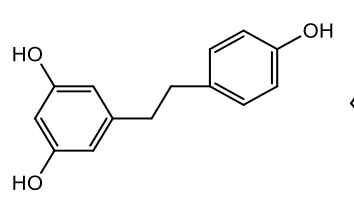

Resveratrol
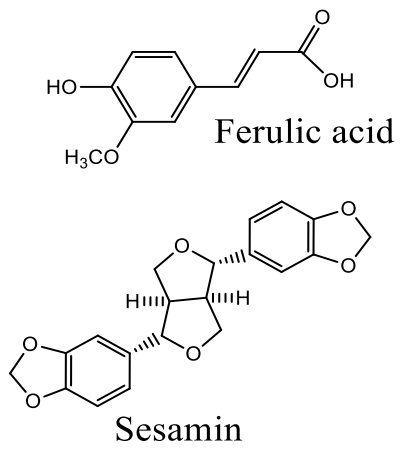

Figure 2: Chemical structures of some selected phenolic compounds in coffee husks.

In spite of these reported data about the presence of phenolic compounds in coffee, Rwanda coffee washing stations are releasing coffee wastes without or with minor treatment, and thus causing environmental pollution. Therefore, a study aiming at addressing these environmental challenges as well as corrosion problems would be foreseen as a significant contribution to Rwandan coffee washing stations. The exploitation of these coffee husks wastes for other useful utilities including anticorrosive materials would be an adequate solution to fight against both environmental pollution and corrosion problems in metallic structures. This study aimed at isolating the phenolic compounds from coffee wastes, regarded as wastes and investigated their corrosion inhibiting properties on mild steel in acidic medium. The results were promising and constituted an alternative way to mitigate corrosion problems.

\section{MATERIALS AND METHODS}

2.1 Preparation of the mild steel sample specimens

Mild steel coupons of $15 \mathrm{~mm}$ diameter and $1 \mathrm{~mm}$ thickness were purchased from DAWASCO (Dar es Salaam Water Sanitation Company) and were used in corrosion tests. Mild steels were firstly abraded with different series of silica carbide papers of variable grades starting with the 320 grifts (coarsest), 400, 800, 1200 and finally 2400 grifts in order to remove surface impurities. Thereafter, they were degreased in analytical grade acetone (99.5\%) followed by ethanol (99\%) rinsing before being weighed after each corrosion experiment. The chemical composition of mild steel coupons was carried out by using SpectroLab Spark Analyser and the results are summarised in Table 1. 


\subsection{Extraction of phenolic compounds}

Coffee husks samples $(5.0 \mathrm{~kg})$ were brought from TWONGEREKAWA cooperative coffee washing station located at Coko Sector in Gakenke District, Rwanda and then transported to the Chemistry Department laboratory of the University of Rwanda. The samples were then subjected to extraction techniques aiming at isolating phenolic compounds as described elsewhere (Dai and Mumper (2010). Coffee husks (1875.6 g) were put on aluminium foil and then dried in oven at $50{ }^{\circ} \mathrm{C}$ for 48 hours while regularly monitoring the weight loss after each 6 hours until a constant mass was attained in order to ensure that there is no remaining moisture content that may hinder extraction of phenolic compounds during extraction step. After being dried, the mass was found to be $379.8 \mathrm{~g}$ ( $20.3 \%$ yield), and then were ground using mortar and pestle to obtain of coffee husks' fine powder $(375.2 \mathrm{~g})$ that was required for extraction. Coffee husks powder (170.2 g) was soaked in $99.5 \%$ acetone $(500 \mathrm{~mL})$ and tightly closed for avoiding air contamination. After maceration technique, the solvent was evaporated using a rotary evaporator under reduced pressures at $40{ }^{\circ} \mathrm{C}$. Then, the acetone crude coffee husks extract were dried in air free desiccator and a mass of $8.2 \mathrm{~g}$ ( $4.8 \%$ yield $)$ was obtained.

\subsection{Chemical characterization of the coffee husks extract}

The tested crude coffee husks extract was subjected to further purification to confirm the presence of phenolic compounds in the mixture. A short column chromatography over silica gel with $n$-hexane/acetone in ratio $1: 4$ as mobile phase was used to purify $100 \mathrm{mg}$ of crude coffee husks extract, which indicated one spot on thin layer chromatography. Thereafter, the solvent system was evaporated to give $30 \mathrm{mg}$ of a pure compound, which was characterised by FTIR and ${ }^{1} \mathrm{H}$-NMR (Figures 3 and 4).

\subsection{Corrosion inhibition efficiency determination by weight loss method}

The mild steel specimens of diameter of $15 \mathrm{~mm}$ and $1 \mathrm{~mm}$ of thickness were used for weight loss experiments. This method was used for determining the corrosion rate, $\left(\mathrm{V}_{\text {corr }}\right)$ and corrosion inhibition efficiency, $(\varepsilon)$ of mild steel coupons in the absence and presence of coffee husks extract (inhibitor) in acidic medium $(1 \mathrm{M} \mathrm{HCl})$. For this purpose, steel coupons were initially weighed using highly sensitive analytical balance (Mettler Toledo) that records mass to fourth decimal digits. 
The weight loss experiments were conducted using mild steel specimens that were immersed in an electrochemical cell containing $1 \mathrm{M} \mathrm{HCl}(50 \mathrm{~mL})$ as corrosion medium without and then with various concentrations (ranging from 0.0 to $800 \mathrm{mg} / \mathrm{L}$ ) of the inhibitor of phenolic crude extract from coffee husks. The effect of temperature was investigated in the absence and presence of a mixture of phenolic coffee husks extract at the minimum inhibitor concentration for temperatures of $25,30,35$ and $40{ }^{\circ} \mathrm{C}$. After the specified period of exposure time in $1 \mathrm{M} \mathrm{HCl}(50 \mathrm{~mL})$, each sample of steel was taken out of the solution and then sonicated in $99.5 \%$ acetone, followed by 99\% ethanol and finally air-dried, before being reweighed. From the weight loss $(w)$ results, the corrosion rate $\left(\mathrm{V}_{\text {corr }}\right)$, degree of surface coverage of the inhibitor $(\theta)$ and corrosion inhibition efficiency $(\eta)$ were calculated using Equations 1, 2 and 3, respectively (Subha and Saratha, 2013).

$$
\begin{aligned}
& \mathrm{V}_{\text {corr }}=\frac{\mathrm{W}}{\mathrm{At}} \\
& \theta=\frac{\mathrm{W}_{\mathrm{bl}}-\mathrm{W}_{\mathrm{inh}}}{\mathrm{W}_{\mathrm{bl}}} \\
& \eta(\%)=\frac{\mathrm{V}_{\mathrm{bl}}-\mathrm{V}_{\mathrm{inh}}}{\mathrm{V}_{\mathrm{bl}}} \times 100
\end{aligned}
$$

where $\mathrm{W}$ is the weight loss in $\mathrm{mg}$, $\mathrm{A}$ is the surface area of mild steel in $\mathrm{mm}^{2}, \mathrm{t}$ is the immersion time in hours (hr), and $\mathrm{W}_{\mathrm{bl}}$ and $\mathrm{W}_{\mathrm{inh}}$ are weight losses in $\mathrm{mg}$ for mild steel in the absence (blank) and presence of inhibitor, respectively, $V_{b l}$ and $V_{\text {inh }}$ are corrosion rates $\left(\mathrm{mg} / \mathrm{mm}^{2} h\right)$ for uninhibited (blank) and inhibited system, respectively.

\section{RESULTS AND DISCUSSION}

\subsection{Chemical characterization of coffee husks waste extract}

The extraction of phenolic compounds from coffee husks waste yields $8.1812 \mathrm{~g}$ of viscous red oily liquid. This corresponds to $4.8 \%$ yield in phenolic compounds. This reported yield is in good agreement with what was reported by Labat et al.2010 on biotechnological potentialities of polyphenolic compounds of coffee where a content of $2.7 \%$ of phenolic compounds was reported (Labat et al.2010. Furthermore, the spectroscopic analysis of the purified coffee husks extract 
was performed and their FT-IR and ${ }^{1} \mathrm{H}-\mathrm{NMR}\left(300 \mathrm{MHz}, \mathrm{CDCl}_{3}\right)$ spectra are presented in Figures 3 and 4 , respectively.

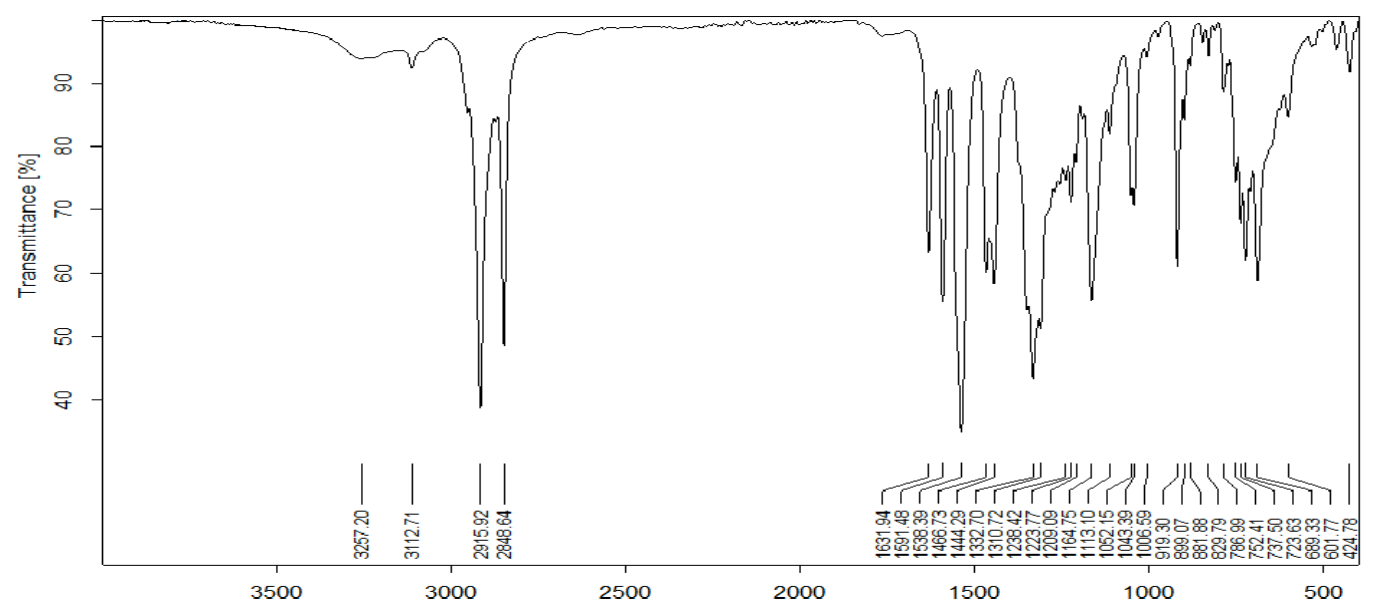

Figure 3: FT-IR spectrum of the main fraction from acetone extract from coffee husks wastes.

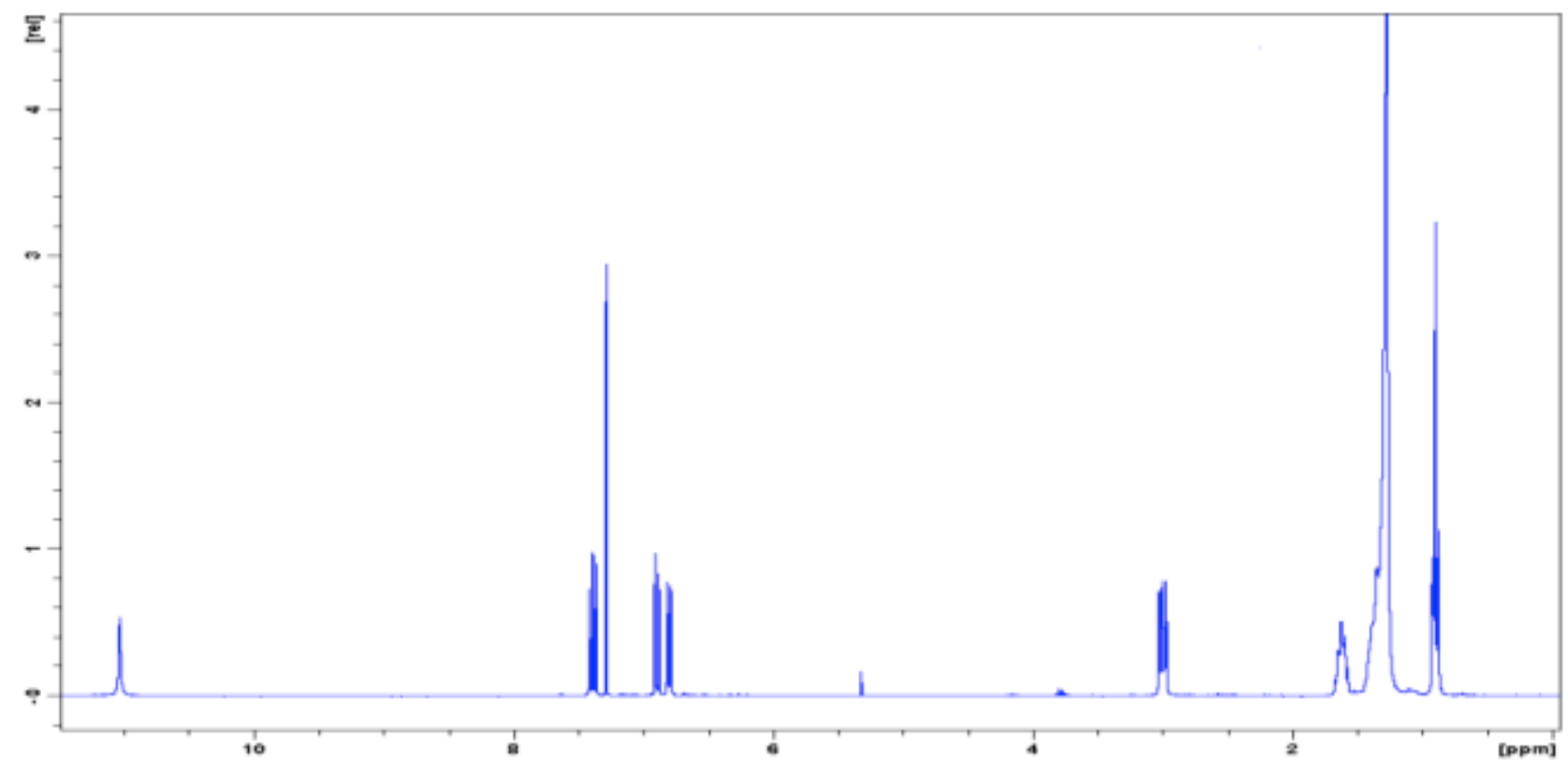

Figure 4: ${ }^{1} \mathrm{H}-\mathrm{NMR}\left(300 \mathrm{MHz}, \mathrm{CDCl}_{3}\right)$ spectrum of the main fraction from acetone extract from coffee husks wastes.

The FT-IR spectrum (Figure 3) indicated a strong absorption at $1538 \mathrm{~cm}^{-1}$, which indicates a stretch of aromatic ring. The peaks that appear at $2914 \mathrm{~cm}^{-1}$ and $2848 \mathrm{~cm}^{-1}$ could be attributed to $\mathrm{C}-\mathrm{H}$ stretches for an $\mathrm{sp}^{2}$ hybridised carbon of alkene functionality $(\mathrm{C}=\mathrm{C}-\mathrm{H})$ and aliphatic $\mathrm{C}-\mathrm{H}$ in $\mathrm{sp}^{3}$ hybridized carbon, respectively. An intense absorption band at $1444 \mathrm{~cm}^{-1}$ is for $\mathrm{C}=\mathrm{C}$ bending. 
The existence of both - $\mathrm{OH}$ and aromatic ring gives an insightful information for the existence of phenolic compounds in the extract and this was confirmed by the existence of strong absorption bands at $1332-1239 \mathrm{~cm}^{-1}$ and $752-601 \mathrm{~cm}^{-1}$ corresponding to the C-O phenol stretching and the aromatic $\mathrm{sp}^{2}$ bending, respectively. Furthermore, the peak at $1310 \mathrm{~cm}^{-1}$ is for $-\mathrm{OH}$ attached to the aromatic ring (Ar-OH). In addition, the FT-IR spectral results indicated a broad absorption band in the range of $3500-2500 \mathrm{~cm}^{-1}$ and a sharp absorption band at $1631 \mathrm{~cm}^{-1}$ corresponding to $-\mathrm{OH}$ stretch and to $\mathrm{C}=\mathrm{O}$ stretches, respectively, which is carboxylic acid. The presence of a carboxylic functional group $(-\mathrm{COOH})$ is confirmed although it was not clearly observed in the range of $3500-2500 \mathrm{~cm}^{-1}$ due to overlap with $-\mathrm{OH}$ in phenol that were observed from $3400-2400 \mathrm{~cm}^{-1}$. The shift of carbonyl functional group that was observed suggests that there might be a conjugation of carbonyl functionality with the aromatic ring. Therefore, the FT-IR spectral results showed that the coffee husks extract contain phenolic compounds. These reported results are in good agreement with what was previously reported by other literatures (Dai and Mumper, 2010).

In Figure 4, the ${ }^{1} \mathrm{H}-\mathrm{NMR}\left(300 \mathrm{MHz}, \mathrm{CDCl}_{3}\right.$ ) spectrum for a compound isolated from the mixture of coffee husks extract, it is clearly seen that a chemical shift for proton at $\delta_{\mathrm{H}} 11.0 \mathrm{ppm}$ (singlet, $2 \mathrm{H})$ are for carboxylic functionality and phenolic proton due to their fast proton exchange. The chemical shifts in the range of $\delta_{\mathrm{H}} 6.7-7.5 \mathrm{ppm}$ can be attributed to the set of protons of the aromatic ring at different positions. A set of protons that are observed in the range $\delta_{\mathrm{H}} 0.9-1.6$ ppm are for aliphatic protons peaks that are in methylene and methyl group. The peaks that are observed in the range $\delta_{\mathrm{H}}$ of $4.6-5.9 \mathrm{ppm}$ is for vinylic protons that are internal of the straight chain carbon $(\mathrm{C}=\mathrm{C}-\mathrm{H})$.

The combination of FT-IR and ${ }^{1} \mathrm{H}-\mathrm{NMR}$ spectral results confirmed that the isolation of the phenolic compounds was successful performed. Moreover, the purified extract may contain phenolic compounds that are carboxylic (benzoic acid) derivative-type. The structure elucidation could not be completed because of lack of ${ }^{13} \mathrm{C}$-NMR and mass spectrometry spectral. However, phenolic compounds were undoubtedly confirmed to be present in the acetone coffee husks extract with a purified main compound resembling to 5-caffeoylquinic acid as supported by available FTIR and ${ }^{1}$ H-NMR (figures 3 and 4).

3.2 Evaluation of corrosion inhibiting properties of coffee husks extract on mild steel 


\subsubsection{Effect of coffee husks extract on chemical potential}

In order to evaluate the corrosion inhibiting properties the coffee extract on mild steel materials, it was necessary to determine the chemical composition of the mild steel coupons prior to corrosion studies. For this purpose, the SpectroLab Spark Analyser was used to determine the elemental chemical composition and the results are summarised in Table 1. The results from Table 1 shows clearly that the percentage of iron (98.7\%) was higher than the rest of the other alloying elements and the percentage of carbon $(0.18 \%)$ was found to be in the range of 0.15 $0.30 \%$ for mild steel. In addition, the percentages of silicon $(0.022 \%)$ and manganese $(0.45 \%)$ were also less than 0.5 and $1.5 \%$, respectively as required for mild steel elemental composition. Therefore, these findings undoubtedly confirm that the specimens, which were used in this study were exactly mild steel (Uzorh, 2013).

Table 1: Chemical composition of mild steel in weight percentage (Wt \%)

\begin{tabular}{cccccccccc}
\hline Element & $\mathrm{C}$ & $\mathrm{Ni}$ & $\mathrm{Si}$ & $\mathrm{Cr}$ & $\mathrm{V}$ & $\mathrm{Al}$ & $\mathrm{Mn}$ & $\mathrm{P}$ & $\mathrm{Fe}$ \\
$\mathrm{Wt}(\%)$ & 0.18 & 0.075 & 0.022 & 0.213 & 0.005 & 0.004 & 0.45 & 0.28 & 98.7 \\
\hline
\end{tabular}

Beside this chemical composition and in order to understand the corrosion mechanism of mild steel in acid medium $(1.0 \mathrm{M} \mathrm{HCl})$ as corrosive medium, the measurement of electrochemical potential, $E$ was judged necessary in this study. For this purpose, the glass electrode with $\mathrm{Ag} / \mathrm{AgCl}$ reference electrode was used to monitor electrochemical potential variation and the obtained results (Figure 5) show its variation in the absence and the presence of inhibitor, which is coffee husk extract. 


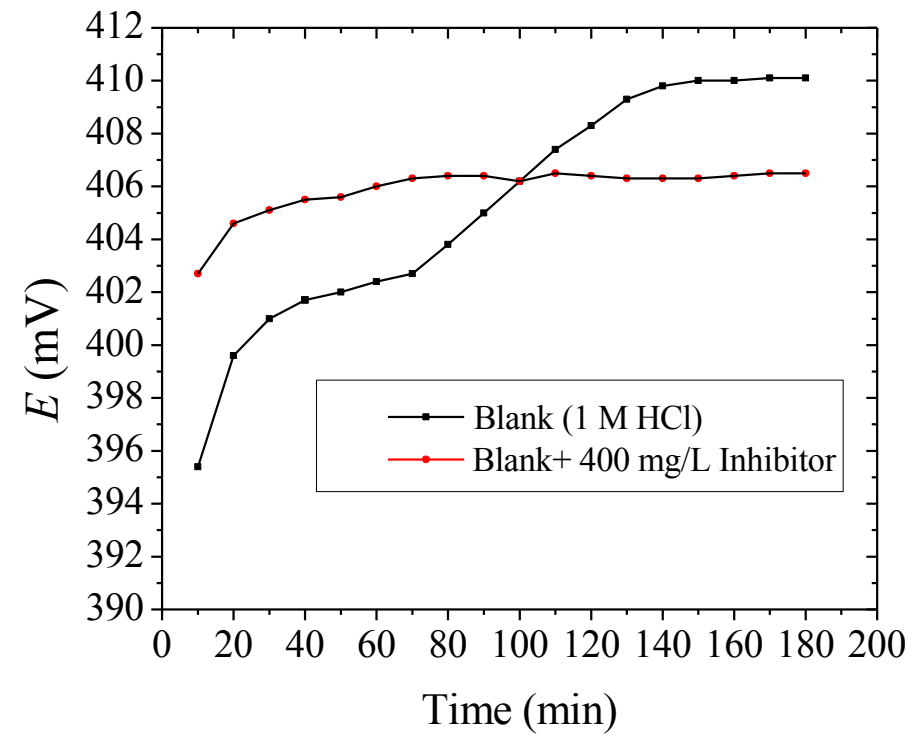

Figure 5: Electrochemical potential $(E)$ versus time curves for mild steel taken within three hours of immersion in $1 \mathrm{M} \mathrm{HCl}$ solution at $25^{\circ} \mathrm{C}$ ).

According to the results in Figure 5, the potential was found to increase with time for both uninhibited and inhibited systems. However, there was a continuous increase for the inhibited solution, while in the uninhibited medium, there was slight fluctuations in the potential, either increasing or decreasing. The obtained data indicated that, with the presence and absence of phenolic extract $(400 \mathrm{mg} / \mathrm{L})$, the potential remained constant after $120 \mathrm{~min}$ and $150 \mathrm{~min}$, respectively. These phenomena may be due to the establishment of steady state conditions in the test solution or corrosive media. In fact, for the case of uninhibited system, formation of a corroded product on mild steel surface, which was isolated from the corrosive media prevented further corrosion and stabilised it. On the other hand, in inhibited system, phenolic compounds bound to the metal surface and isolated it from the corrosive medium and thereby speeding up the establishment of a steady state. Meanwhile, the efficiency of phenolic mixture extract from coffee husks waste in reducing the rate of corrosion of mild steel in $1.0 \mathrm{M} \mathrm{HCl}$ was remarked through the rapid stabilisation of corrosion phenomenon in the inhibited medium within comparison to the corrosive medium without this extract. However, in the absence of coffee husks extract, the small fluctuation toward constant potentials $(410 \mathrm{mV})$ that were observed from $150 \mathrm{~min}$ to $180 \mathrm{~min}$ ( 3 hours) could be due to the existence of dynamic diffusion process of corrosive species (even though it was at lower extent) through the thin layer of the corrosion product that was formed on mild steel surface (Philip et al, 2016). 


\subsubsection{Effect of inhibitor concentration on corrosion of mild steel in $1 \mathrm{M} \mathrm{HCl}$}

In order investigate the corrosion inhibiting properties of coffee husk extract on the corrosion of mild steel in acidic medium $(1.0 \mathrm{M} \mathrm{HCl})$, various concentrations of the extract were tested. These tests were realised in comparison with the control test which was performed without any extract. The obtained results indicated that the rate of corrosion decreased with the increase in the concentration of coffee husks extract while inhibition efficiency was found to increase (Table 2 and Figure 6).

Table 2: Corrosion parameters for mild steel in $1 \mathrm{M} \mathrm{HCl}$ at various concentrations of a mixture of phenolic compounds from coffee husks extract after two hours

\begin{tabular}{llll}
\hline $\mathrm{C}_{\text {inh }}\left(\mathrm{mg} . \mathrm{L}^{-1}\right)$ & $\mathrm{V}_{\text {corr }}\left(\mathrm{mg} \mathrm{mm}^{-2} \mathrm{hr}^{-1}\right)$ & $\theta$ & $\eta(\%)$ \\
\hline 0.0 & 0.0470 & - & - \\
100 & 0.0154 & 0.673 & 67.3 \\
200 & 0.0094 & 0.799 & 79.9 \\
400 & 0.0064 & 0.865 & 86.5 \\
800 & 0.0066 & 0.859 & 85.9 \\
\hline
\end{tabular}

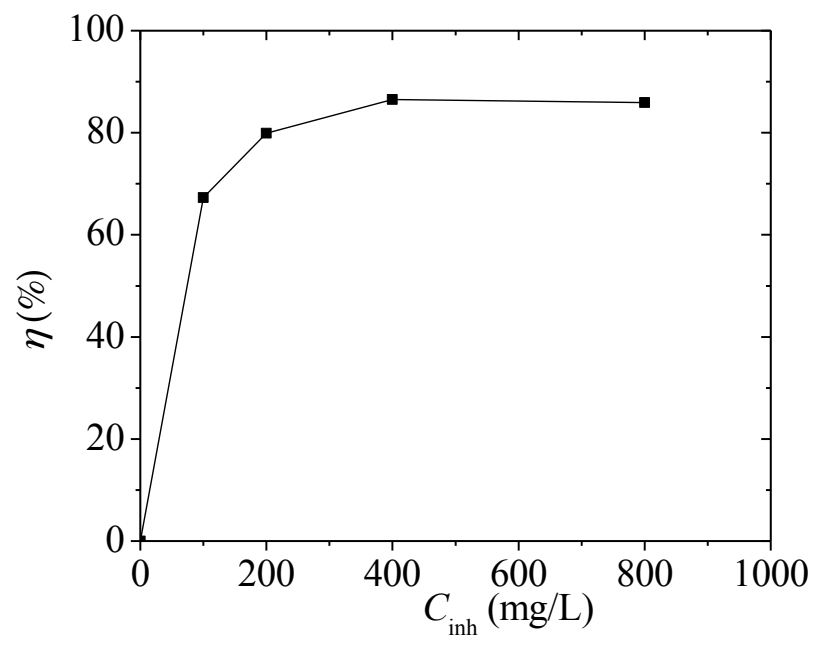

Figure 6: Corrosion inhibition efficiency versus inhibitor concentration in $1 \mathrm{M} \mathrm{HCl}$.

The decrease in corrosion rates and the increase of inhibition efficiency with inhibitor concentration may be attributed to the adsorption of phenolic compounds onto mild steel surface, thereby preventing/reducing the mass transfer in the corrosive medium and consequently slowing down the mild steel corrosion process. These findings are in good agreement with those reported in other studies for the use plant extract in corrosion inhibition mechanisms (Nwosu and Muzakir, 2016, Ragendran et al., 2016). In this study, it was shown that the inhibition efficiency 
increased upon the adsorbed inhibitor surface coverage, which in turn increased with inhibitor concentration in the corrosive medium ( $1 \mathrm{M} \mathrm{HCl}$ solution). In addition, the twofold action of the addition of the inhibitor shows that the inhibitor was adsorbed on the metal surface through monolayer mechanism (Subha and Saratha, 2013). Furthermore, from Figure 6, it is clearly observed that the corrosion inhibition efficiency increased with inhibitor concentration and the minimum inhibitor concentration required to give the optimum inhibition efficiency was 400 $\mathrm{mg} / \mathrm{L}$, where the highest value of corrosion inhibition efficiency $(86.5 \%)$ was achieved. These results are in good agreement with those reported by Vasconcelos et al. (2011) for mild steel materials and by Fouda et al. (2015) for aluminium materials.

\subsubsection{Effect of temperature on corrosion rate}

To determine the effect of temperature on the corrosion rate and on the corrosion inhibition efficiency experiments were performed at various temperatures varying between 25 and $40{ }^{\circ} \mathrm{C}$. The study indicated that corrosion rates increased with temperature for the uninhibited system (1 $\mathrm{M} \mathrm{HCl}$ corrosive medium) for the first two hours and thereafter, it decreased for all investigated temperatures (Table 3 and Figure 6).

Table 3: Corrosion parameters for mild steel in $1 \mathrm{M} \mathrm{HCl}$ at various time intervals and temperatures in the absence and presence of $400 \mathrm{mg} / \mathrm{L}$ of coffee husks extract

\begin{tabular}{lllll}
\hline $\begin{array}{l}\text { Temperatures } \\
\left({ }^{\circ} \mathrm{C}\right)\end{array}$ & $\begin{array}{l}\text { Time } \\
\text { (hours) }\end{array}$ & $\begin{array}{l}\mathrm{V}_{\text {corr }} \text { without inhibitor } \\
\left(\mathrm{mg} . \mathrm{mm}^{-2} \cdot \mathrm{hr}^{-1}\right)\end{array}$ & $\begin{array}{l}\mathrm{V}_{\text {corr }} \text { with inhibitor } \\
\left(\mathrm{mg} \cdot \mathrm{mm}^{-2} \cdot \mathrm{hr}^{-1}\right)\end{array}$ & $\begin{array}{l}\eta \\
(\%)\end{array}$ \\
\hline \multirow{3}{*}{25} & 1 & 0.015 & 0.010 & 33.3 \\
& 2 & 0.047 & 0.007 & 86.5 \\
& 3 & 0.038 & 0.015 & 60.5 \\
& 5 & 0.017 & 0.009 & 47.2 \\
\hline \multirow{3}{*}{30} & 1 & 0.042 & 0.030 & 28.5 \\
& 2 & 0.071 & 0.013 & 82.1 \\
& 3 & 0.028 & 0.012 & 56.2 \\
& 5 & 0.035 & 0.022 & 37.1 \\
\hline 35 & 1 & 0.017 & 0.013 & 23.2 \\
& 2 & 0.081 & 0.019 & 76.1 \\
& 3 & 0.060 & 0.0307 & 48.8 \\
& 5 & 0.040 & 0.0278 & 30.1 \\
\hline \multirow{3}{*}{40} & 1 & 0.015 & 0.012 & 20.2 \\
& 2 & 0.121 & 0.032 & 72.9 \\
\hline
\end{tabular}



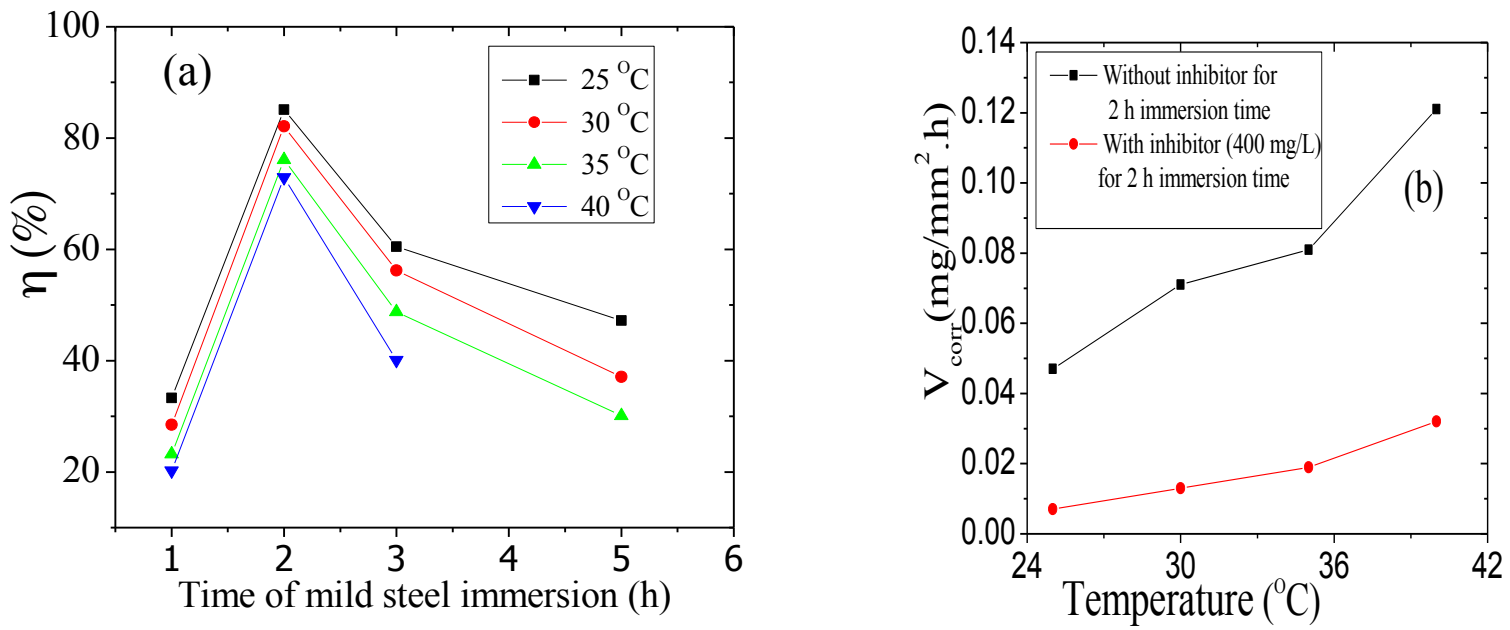

Figure 7: (a)Variation of corrosion inhibition efficiency with time and (b) corrosion rates for mild steel in $1.0 \mathrm{M} \mathrm{HCl}$ at different temperatures.

These observations in Figure 7could be attributed to state of the system where the corrosion product was stable to the surface of mild steel, thus isolating it from the media and consequently preventing further of corrosion (Salahinejad et al., 2013). Table 3 results also showed that the inhibition efficiency decreased with temperature. This is due to higher diffusion rate of molecules in the corrosive medium that are developed at higher temperatures, thus offering possibility of reaching the mild steel surface and end up by enhancing its dissolution. Furthermore, it can be argued that the corrosion rates increased with the temperature because at higher temperatures, the formation of unstable corrosive product/layer can be decomposed and thereby exposing more surface of mild steel to corrosion. These observations for corrosion rate of mild steel in acidic media are in good agreement with those reported by Nwosu and Muzakir (2016). Based on the results in Table 3 and Figure 7, it is clearly seen that coffee husks extract are able to inhibit mild steel corrosion in $1.0 \mathrm{M} \mathrm{HCl}$ for the first two hours at $25^{\circ} \mathrm{C}$ since its inhibition efficiency $(86.5 \%)$ was found to be higher than others. This is due to the fact that higher temperatures favour desorption and later dissociation of the inhibitor-metal complex that was already adsorbed on the mild steel surface. These findings are in good agreement with those reported by Founda et al., (2013).

\subsubsection{Adsorption isotherms and thermodynamic parameters}


The adsorption isotherm models provide the nature of interactions between the inhibitor on the metal surface. For this purpose, the surface coverage $(\theta)$ and inhibitor concentration $\left(\mathrm{C}_{\text {inh }}\right)$ were used to ascertain the type of adsorption model at $25{ }^{\circ} \mathrm{C}$. The Langmuir, Temkin and Frumkin adsorption isotherms were tested and parameters are summarised in Table 4. The Langmuir, Temkin and Frumkin adsorption isotherms are characterised by Equations 4, 5 and 6, respectively (Philip et al., 2016).

$$
\begin{aligned}
& \log \left(\frac{\theta}{1-\theta}\right)=\log \mathrm{K}_{\mathrm{ads}}+\log \mathrm{C}_{\mathrm{inh}} \\
& \theta=-\frac{2.303}{2 \alpha} \log \mathrm{K}_{\mathrm{ads}}-\frac{2.303}{2 \alpha} \log \mathrm{C}_{\mathrm{inh}} \\
& \log \left[\frac{\theta}{(1-\theta) \mathrm{C}_{\mathrm{inh}}}\right]=\log \mathrm{K}_{\mathrm{ads}}+\frac{2 \alpha}{2.303} \theta
\end{aligned}
$$

where $\mathrm{C}_{\mathrm{inh}}$ is the inhibitor concentration, $\mathrm{K}_{\mathrm{ads}}$ is the adsorption equilibrium constant, $\alpha$ is the attractive parameter between the already adsorbed inhibitors and $\theta$ is the degree of the surface coverage which is between 0 and 1 (Dominic and Monday, 2016).

For the Langmuir adsorption isotherm model, a plot of $\log \left(\frac{\theta}{1-\theta}\right)$ versus $\log C_{\text {inh }}$ is expected to give a straight line with slope equal to unit and intercept $\log \mathrm{K}_{\mathrm{ads}}$ while the Temkin adsorption isotherm is obeyed when the plot $\theta$ versus $\log C_{\text {inh }}$ gives a straight line with slope equals to $-\frac{2.303}{2 \alpha}$ and intercept equal to $-\frac{2.303}{2 \alpha} \operatorname{logK}_{\text {ads }}$ (Nwabanne and Okafor, 2012).

The Frumkin adsorption isotherm model is obeyed when the plot $\log \left[\theta /(1-\theta) \mathrm{C}_{\mathrm{inh}}\right]$ versus $\theta$ gives a straight line with $y$-intercept, $\log \mathrm{K}_{\mathrm{ads}}$ and slope 2a/2.303 (Aziz and Sirat, 2015). The determination of the adsorption equilibrium constant enables the determination the Gibbs free energy for the adsorption of the inhibitor onto mild steel surface as given by Equation 7.

$$
\Delta \mathrm{G}_{\mathrm{ads}}=-2.303 \mathrm{RT} \log \left(55.5 \mathrm{~K}_{\mathrm{ads}}\right)
$$

Table 4: Adsorption parameters for corrosion inhibition of mild steel in $1 \mathrm{M} \mathrm{HCl}$ by using coffee husks extract at $25^{\circ} \mathrm{C}$. 


\begin{tabular}{lcccc}
\hline Adsorption Isotherms & $\mathrm{R}^{2}$ & Slopes & $\log \mathrm{K}_{\mathrm{ads}}$ & $\Delta \mathrm{G}\left(\mathrm{kJ} . \mathrm{mol}^{-1}\right)$ \\
\hline Langmuir & 0.98916 & 0.989 & 1.15 & -16.51 \\
Temkin & 0.81690 & 0.207 & 1.40 & -17.94 \\
Frumkin & 0.70580 & -0.507 & 0.67 & -13.78 \\
\hline
\end{tabular}

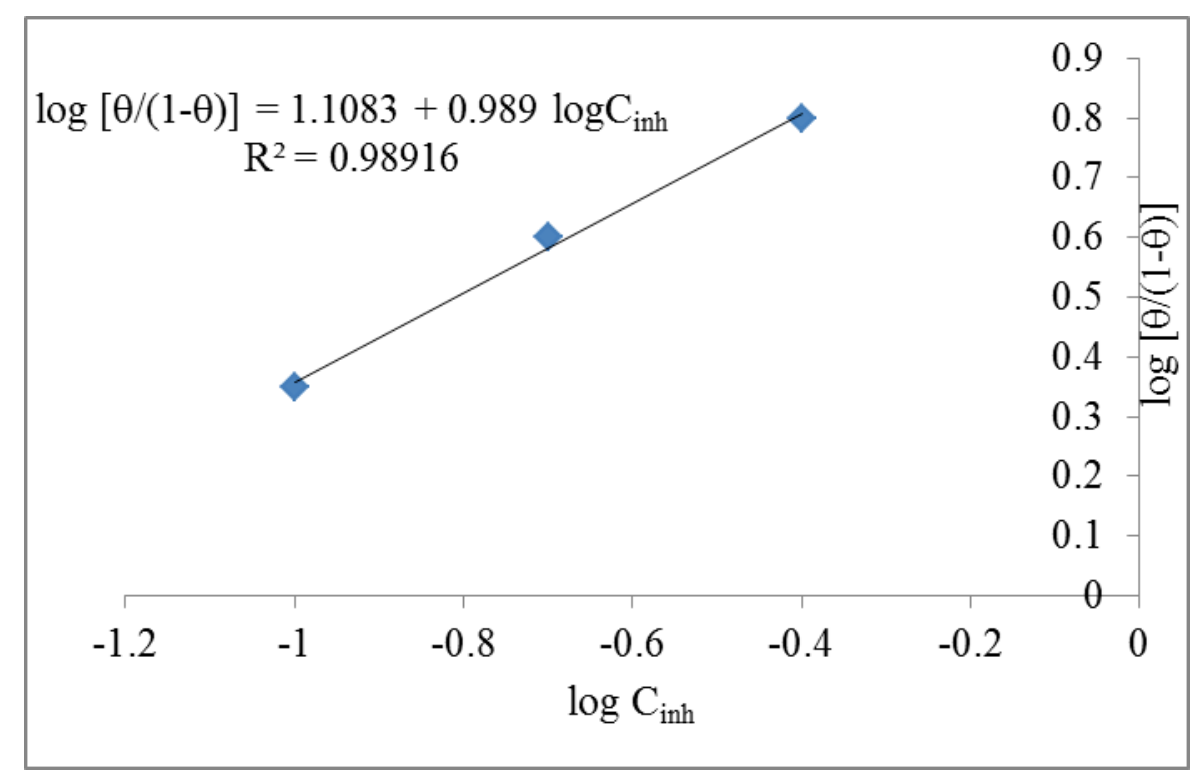

Figure 8: Langmuir adsorption isotherm plot for mild steel in $1 \mathrm{M} \mathrm{HCl}$ at various concentrations of phenolic compounds extract at $25^{\circ} \mathrm{C}$

From the results in the Table 4 and Figure 8, it is clearly seen that the adsorption parameters were excellently fitted to the Langmuir adsorption isotherm model because its correlation coefficient $\left(R^{2}\right)$ equals to 0.98916 was closer to 1.0 while the ones for the Temkin and Frumkin adsorption isotherms were found to be 0.81690 and 0.70580 . Furthermore, Table 4 and Figure 8 show that the plot of the Langmuir adsorption isotherm for coffee husks extract (corrosion inhibitor) is characterised by a slope equals to 0.989 , which is closer to unit as theoretically expected (Subha and Saratha, 2013). Therefore, mechanistically, there was no lateral interaction between already adsorbed phenolic compounds (corrosion inhibitor) and the adsorption was forming monolayers on the mild steel surface (Ibrahim and Habbab, 2011). In addition, as from Table 4 , the value of $\Delta G_{\text {ads }}$, which is equal to $-16.51 \mathrm{~kJ} \cdot \mathrm{mol}^{-1}$ pointed out that the adsorption was spontaneous and characterised by predominance of physical adsorption mechanism since the value of $\Delta G_{\text {ads }}$ was negative and less than $-20 \mathrm{~kJ} \mathrm{~mol}^{-1}$ (Abeng et al., 2017). These results are in good agreement with inhibition efficiency results that decreased with the increase in temperature. 
The occurrence of physisorption on mild steel immersed in acidic medium may be related to the interaction of phenolic compounds that were found in the coffee husks. In addition, it may be due the protonated lone pairs of oxygen in $-\mathrm{OH}$ functional group and $\pi$ - electron systems in $\mathrm{C}=\mathrm{C}$ functionality as well as charges from weak dissociation carboxylic (-COOH) functional group in phenolic extract of coffee husks (Buchweishaija, 2009). The formation of a charged layer over mild steel surface isolated the mild steel from corrosive species $\left(\mathrm{H}^{+}, \mathrm{Cl}^{-}\right.$and water) and prevented it from further corrosion, consequently slowing down the corrosion process of mild steel in the presence of inhibitor (Ang et al., 2017).

Thermodynamic and kinetics parameters were obtained using the Arrhenius and Eyring models that enabled the discussion of the adsorption mechanism of the inhibitor on the mild steel surface. The activation energy $\left(\mathrm{E}_{\mathrm{a}}\right)$ values were determined from the Arrhenius plot ( $\ln \mathrm{V}_{\text {corr }}$ vs 1/T) for the corrosion of mild steel using the Arrhenius Equation 8 and Figure 9 while activation enthalpy, $\left(\Delta H^{*}\right)$ and entropy, $\left(\Delta S^{*}\right)$ were deduced from the Eyring Equation 9 and Figure 10 (Saha et al., 2015). The results of $\mathrm{E}_{\mathrm{a}}, \Delta \mathrm{S}^{*}$ and $\Delta \mathrm{H}^{*}$ are summarised in Table 5.

$$
\begin{gathered}
\log \mathrm{V}_{\text {corr }}=\log \mathrm{A}-\frac{\mathrm{E}_{\mathrm{a}}}{2.303 \mathrm{RT}} \\
\ln \left(\frac{\mathrm{V}_{\text {corr }}}{\mathrm{T}}\right)=\left[\frac{\Delta \mathrm{S}^{*}}{\mathrm{R}}+\ln \left(\frac{\mathrm{R}}{\mathrm{hN}}\right)\right]-\frac{\Delta \mathrm{H}^{*}}{\mathrm{RT}}
\end{gathered}
$$

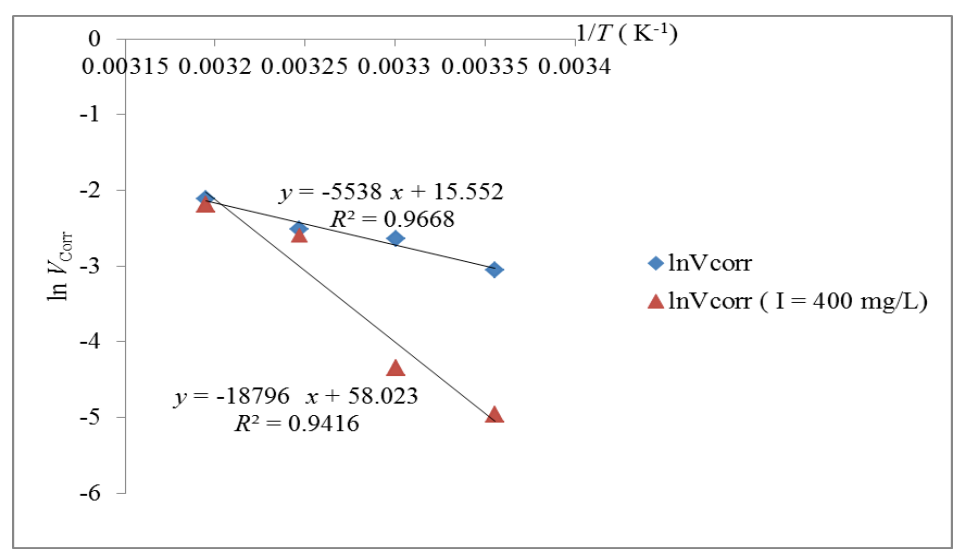

Figure 9: Arrhenius plot for mild steel in $1 \mathrm{M} \mathrm{HCl}$ solution in the absence and presence of 400 $\mathrm{mg} / \mathrm{L}$ of coffee husks extract. 


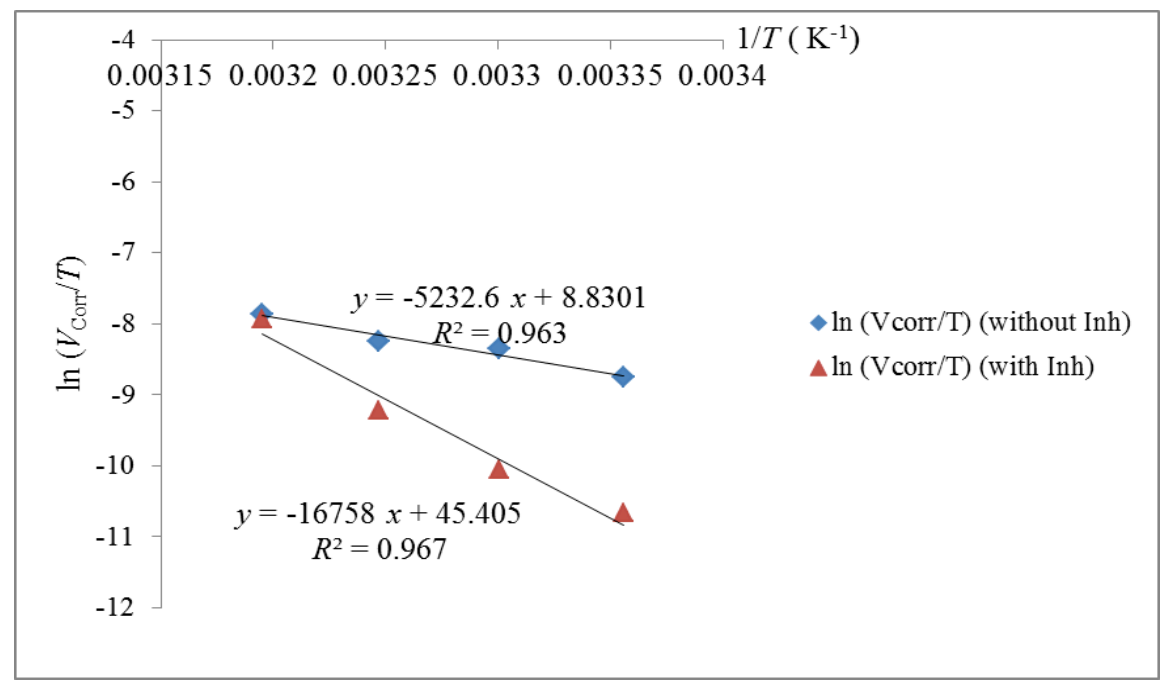

Figure 10: Eyring plot for mild steel in $1 \mathrm{M} \mathrm{HCl}$ in the absence and presence of the coffee husks phenolic extract inhibitor at concentration of $400 \mathrm{mg} / \mathrm{L}$.

Table 5: Kinetics and thermodynamic parameters for mild in steel $1 \mathrm{M} \mathrm{HCl}$ without and with inhibitor of phenolic coffee husks extract $(400 \mathrm{mg} / \mathrm{L})$.

\begin{tabular}{llll}
\hline $\mathrm{C}_{\text {inh }}(\mathrm{mg} / \mathrm{L})$ & $\mathrm{E}_{\mathrm{a}}\left(\mathrm{kJ} \cdot \mathrm{mol}^{-1}\right)$ & $\Delta \mathrm{H}^{*}\left(\mathrm{~kJ} \cdot \mathrm{mol}^{-1}\right)$ & $\Delta \mathrm{S}^{*}\left(\mathrm{~kJ} \cdot \mathrm{mol}^{-1} \cdot \mathrm{K}^{-1}\right)$ \\
\hline 0.0 & 46.04 & 42.5 & -124.07 \\
400 & 156.29 & 139.3 & 179.7 \\
\hline
\end{tabular}

As from Table 5 results, it is clearly seen that the value of the activation energy was increased, from 46.04 to $156.29 \mathrm{~kJ} . m o l^{-1}$ due to the addition of coffee husks extract ( $\left.400 \mathrm{mg} / \mathrm{L}\right)$ that were adsorbed on mild steel surface and hinder corrosion process. Therefore confirming that phenolic coffee husks extract acted as a corrosion inhibitor (Saqalli et al., 2015). In addition, the value of $\Delta \mathrm{H}^{*}$ in the presence of inhibitor is also higher than the one in the absence of coffee husks extract. As both values of enthalpy are positive (endothermic process), this signifies that the dissolution of mild steel became more laborious in the presence of the coffee husks (400 mg/L). Furthermore, the table 5 results indicated that the values of $\mathrm{E}_{\mathrm{a}}$ and $\Delta \mathrm{H}^{*}$ in the presence of inhibitor (coffee husks) are higher than those without inhibitor, which give an insightful information that less stable products were formed from corrosion such as evolution of hydrogen gas at the cathode electrode. These findings are in good agreement with those reported by Saqalli et al, (2015). The increase of the value of $\Delta \mathrm{S}^{*}$ also indicated that there was much disorder during the course of corrosion, specifically in the transition state and formation of the activated 
complex. This could be probably due to the substitution of adsorbed water molecules on mild steel surface by phenolic compounds in the coffee husks and thereby slowing down the mild steel dissolution while favouring hydrogen evolution from cathode reduction. Consequently, in the rate-determining step of the corrosion inhibition process, the transition state structure favoured the dissociation rather than association mechanism (Subha and Saratha, 2013).

\section{Conclusion}

In this study, a mixture of phenolic compounds was extracted from coffee husks by using acetone solvent, characterised and then investigated for corrosion inhibiting properties on mild steel in $1 \mathrm{M} \mathrm{HCl}$ by weight loss method. The FT-IR and ${ }^{1} \mathrm{H}-\mathrm{NMR}$ spectral results confirmed undoubtedly the presence of phenolic compounds that are carboxylic phenolic type compounds.

Kinetics and thermodynamic parameters were determined in order to gain better understanding of the efficiency of the extracted phenolic compounds on mild steel in acidic medium for temperature between $25-40^{\circ} \mathrm{C}$ under stationary conditions for mimicking industrial acid picking process. The results showed that the activation energy $(156.29 \mathrm{~kJ} / \mathrm{mol})$ in the presence of phenolic compound extract from coffee husks was greater than the one without them (46.04 $\mathrm{kJ} / \mathrm{mol}$ ), therefore, phenolic compounds extracted from coffee husks wastes exerted the corrosion inhibition through adsorption effects that hindered corrosion process. It was found that the corrosion rates decreased with the inhibitor concentration while the inhibition efficiency increased with the concentration of the coffee husks extract. However, the inhibition efficiencies were found to decrease with the increase in temperature from 25 to $40{ }^{\circ} \mathrm{C}$. The optimum inhibition efficiency of $86.5 \%$ was achieved within two hours for an inhibitor concentration of $400 \mathrm{mg} / \mathrm{L}(400 \mathrm{ppm})$ of phenolic compounds extract from coffee husks under stationary condition at $25^{\circ} \mathrm{C}$.

The thermodynamic parameters such as adsorption equilibrium constant, enthalpy and Gibbs free energy revealed that the adsorption of phenolic compounds (in the coffee husks extract) on mild steel surface was effected through physical adsorption mechanism. Furthermore, the adsorption mechanism was found to obey the Langmuir adsorption isotherm model, which suggested that the adsorption of the corrosion inhibitor was effected through monolayer formation and there 
was no lateral or vertical interaction between neighbouring phenolic groups that were already physisorbed.

Consequently, these findings about corrosion inhibiting properties of phenolic compounds extracted from coffee husks wastes are opening more interest to evaluate their cytotoxicity as well as the lifetime once they are used as corrosion inhibitors.

As for an on-going research project to value the coffee husks wastes from coffee washing stations in Rwanda, it is worth mentioning that chemical structure elucidation for phenolic compounds and other phytochemical constituents in coffee husks wastes should be completed in order to effectively solve environmental challenges that are related to waste from coffee washing stations.

\section{ACKNOWLEDGEMENTS}

The authors are thankful for the Department of chemistry of College of Science and Technology, University of Rwanda and Chemistry Department of the University of Dar es Salaam for Laboratory analysis facilities that were provided during the research. It is in this regard that $\mathrm{Mr}$. Mardoche M. Birori, Mr. Emmanuel Nkurunziza, Mr. Hubert Rudakemwa, Mr. Pius Godefrey and Marisa are highly acknowledged. The authors also keep special thanks to the International Science Program (ISP), University of Uppsala for partial funding this research. Lastly, the authors also acknowledge Mr. Jean Pierre Kwizera for providing sampling facilities and his commitment to help the sampling team during coffee husks waste sample collection from TWONGEREKAWA coffee washing station.

\section{REFERENCES}

Abeng, F. E., Idim, V. D., Obono, O. E. and Magu, T. O. (2017). Adsorption and adsorption isotherm: application to corrosion inhibition studies of mild steel in $2 \mathrm{M} \mathrm{HCl}$. WSN, 77: 298-313.

Ang, W., Wang, Q., Xu, K., Yin, Y., Bao, H., Li, X. and Chen, S. (2017). Enhanced corrosion resistance of carbon steel in hydrochloric acid solution by Eriobotrya japonica. Materials, 10: $2-513$.

Aziz, M., and Sirat, H. M. (2015). Turmeric and ginger as green inhibitors of mild steel 
corrosion in acidic medium. J. Mater. Env. Sci. 6: 1480-1487.

Buchweishaija J. (2009) Phytochemicals as green corrosion inhibitors in various corrosive media: A review article. Tanz. J. Sci. 35: 78-92.

Dai, J. and Mumper, R. J. (2010). Plant phenolics: Extraction, analysis and their antioxidant and anticancer properties. Molecules 15: 7313-7352.

Dominic, O. O. and Monday, O. (2016). Optimization of the inhibition efficiency of mango extract as corrosion inhibitor of mild steel in $1.0 \mathrm{M} \mathrm{H}_{2} \mathrm{SO}_{4}$ using response surface methodology. J.Chem. Tech. Metal. 51: 302-314.

Frah, A. and Donangelo, C. M. (2006) Phenolic compounds in coffee. Braz. J. Plant Physiol. 18: 23-36.

Fouda, A. S., Gadow, H. S. and Shalabi, K. (2015). Chemical and electrochemical investigations of coffee husks as green corrosion inhibitor for aluminum in hydrochloric acid solutions. IJRRAS 23: 28-45.

Ghareba, S. and Omanovic, S. (2011). 12-Aminododecanoic acid as a corrosion inhibitor for carbon steel. Electrochimica Acta. 56: 3890-3898.

Hariom, K. H., Pradeep, H and Bala, A. (2016). Corrosion inhibition of mild steel by using hexylamine as corrosion inhibitor in acidic medium. Der Pharma Chemica. 8: 268-278.

Ibrahim, T. and Habbab, M. (2011). Corrosion inhibition of mild steel in $2 \mathrm{M} \mathrm{HCl}$ using aqueous extract of Eggplant peel. Int. J. Electrochem. Sci. 6: 5357-5371.

Nwabanne, J. T. and Okafor, V. N. (2012). Adsorption and thermodynamics study of the inhibition of corrosion of mild steel in $\mathrm{H}_{2} \mathrm{SO}_{4}$ medium using Vernonia amygdalina. J.MMCE. 2012: 885-890.

Nwosu, F. O. and Muzakir, M. M. (2016). Thermodynamic and adsorption studies of corrosion inhibition of mild steel using lignin from siam weed (Whromolaena odorata) in acid medium. J. Mater. Envir. Sci. 7: 1663-1673.

Philip, Y. J. N., Buchweshaija, J. and Mwakalesi, A. (2016). Corrosion inhibition of amino pentadecylphenols (APPs) derived from cashew nut shell liquid on mild steel in acidic medium. Material Science and Applications, 7: 396-402.

Presenter, A. L. C., Waite, S. W. and Nelsen, D. K. (2005). Technical article corrosion and corrosion enhancers in amine systems presented at the Brimstone sulfur conference, MPR Services, Inc. 2005: 1-19. 
Rajendran, S., Ganga Sri, V., Arockiaselvi, J. and Amalraj, A. J. (2005). Corrosion inhibition by plant extract - An overview. Bulletin of Electrochemistry, 21: 30-49.

Rani, B. E. A. and Basu, B. B. J. (2012). Green inhibitors for corrosion protection of metals and alloys : An overview. Int. J. Corr. 2012: 1-15.

Salahinejad, E., Hadianfard, M. J., Macdonald, D. D., Sharifi-Asl, S., Mozafari, M., Walker, K. J. and Tayebi, L. (2013). In vitro electrochemical corrosion and cell viability studies on nickel-free stainless steel orthopedic implants. PLOS ONE. 8: 1-8.

Saqalli, L., Galai, M., Benhiba, M., Gharda, N., Habbadi, N., Ghailane, R. and Touir, R. (2015). Experimental and theoretical studies of alizarin as corrosion inhibitor for mild steel in $1.0 \mathrm{M}$ $\mathrm{HCl}$ solution. JMES. 8: 458-466.

Senthil, D., Saratha, R. and Vasantha, R. (2016) Corrosion inhibition of mild steel in hydrochloric acid medium using plant extract - A succinct review. IJSETR. 5: 3324-3340.

Singh, A., Talha, M., Xu, X., Sun, Z. and Lin, Y. (2017). Heterocyclic corrosion inhibitors for J55 steel in a sweet corrosive medium. ACS Omega, 2: 8177-8186.

Subha, R. and Saratha, R. (2013). Inhibitive action of Helianthus annus linn Extract on corrosion of Mild steel in $1 \mathrm{~N}$ hydrochloric acid medium. Int. J. Chem. Res. 2: 1-14.

Uhlig, H. H. and Revie R. W. (2015) Corrosion and corrosion control: an introduction to corrosion science and engineering. $4^{\text {th }}$ Edition, John Wiley and Sons, Inc.p. 1-353.

Uzorh, E. A. C. (2013). Corrosion properties of plain carbon steels. IJES. 2: 1-7.

Vasconcelos, V., Salgado, R., Faia, C., Sá, D., Lopez, T., Alberto, C. and Elia, E. D. (2011). Inhibitory action of aqueous coffee ground extract on the corrosion of carbon steel in $\mathrm{HCl}$ solution. Corrosion Science 53: 2385-2392. 